\title{
Soil Forest Ecosystem and Forest Fire Effect on Soil Organic Carbon Stock in Lebanon
}

\author{
Darwish Talal ${ }^{1}$, Abou Daher Mohamad ${ }^{2}$, Jomaa Ihab $^{3}$, Faour Ghaleb ${ }^{1}$, Awad Mohamad ${ }^{1}$ and Hamze Mouin ${ }^{4}$ \\ 1. National Council for Scientific Research, Centre for Remote Sensing, Beirut 8281/11, Lebanon \\ 2. Head of Educational Department/MsC, Ministry of Agriculture, Beirut 8281/11, Lebanon \\ 3. Lebanese Agricultural Research Institute, Tal Amara, Bekaa, Zahle 287, Lebanon \\ 4. National Council for Scientific Research, Beirut 8281/11, Lebanon
}

\begin{abstract}
Accurately quantifying SOC (soil organic carbon) store in soils is considered fundamental to global climate change modeling, notably in soil forest ecosystems in relation to land cover/use change, forest fires and sustainable land management practices. Lebanese soils were described as relatively poor in organic matter content. This work used Landsat and IRS (Indian Remote Sensing) to classify land cover and land use, field survey to map the soil cover and assess carbon stock in the Lebanese soil and forest ecosystems and link the frequency of forest fires with the soil nature and land cover land use to assess the resulting risk of SOC loss from the soil pool. SOC density and stock was assessed using information from 450 soil profiles and the average OC content in a given soil type was calculated involving organic matter content in the soil, bulk density, soil thickness and the content of coarse fragments to produce the national SOC stock map. A total of 11 soil types (major classes) represented the mapping units describing the higher soil component or major classes were identified in Lebanon. The higher standard deviation observed in Luvisols reflects soil diversity, history and different management. Comparing the results of surface soil layer with the overall SOC density and stock in Lebanese soils showed a good correlation (0.98) between the OC stock within the upper soil layer and in the 100 $\mathrm{cm}$ depth, indicating the absolute role of the upper, biologically most active soil layer in the organic matter accumulation and carbon sequestration. Observation over a pilot area in the High Meten showed the calcareous soil group consists of Luvisols with associated Cambisols. Soil units representing the transition between the two soil groups are markedly affected by erosion-deposition processes. Pine occupies the largest area of forest (3,600 ha) followed by oak (1,800 ha) and mixed forest (1,200 ha), representing $24.9 \%, 12.5 \%$ and $8.2 \%$ of forest cover respectively. The analysis of SOC density in the soil of the pilot area showed relatively higher average organic matter accumulation rate in the soil under forest stands compared to shrubs and agricultural lands both at the soil surface ( 33.5 ton/ha) versus ( 30 ton/ha) and in the entire soil profile (99 ton/ha) versus ( 91 ton/ha) respectively. The burned area on these soil types reached 700 and 1,500 ha in 2003 while in the first soil group it did not exceed 50 ha.
\end{abstract}

Key words: Land cover, mountain pedogenesis, soil organic matter, east mediterranean, fires, drought.

\section{Introduction}

The terrestrial environment is the most important living space for human beings and soils are at the core of all ecosystem services. SOC (soil organic carbon) stocks are nearly three times as large as stocks in the vegetation of terrestrial ecosystems [1] and twice as large as the stocks in the atmosphere [2]. Changes in SOC affect the density of greenhouse gases and emission to the atmosphere, possibly affecting soil

Corresponding author: Darwish Talal, Ph.D., research fields: soil and land degradation. resilience to drought and increasing the impact of global climate change [3]. A good estimation of carbon pools in the soils has been suggested as a means to help mitigate atmospheric $\mathrm{CO}_{2}$ increases and anticipated changes in climate [4]. Accurately quantifying SOC store in soils is considered fundamental to global climate change modelling $[5,6]$, notably in soil forest ecosystems in relation to land cover/use change, forest fires and sustainable land management practices. Forest fires in Lebanon occur frequently and a total of 70,600 forest fire events took place between 1994 and 2004, with an average of 
1,200 ha of forested area burned annually [7]. The preliminary assessment of carbon stock in Lebanese soils was assessed to be equivalent to 40.5 ton $\mathrm{ha}^{-1}$ indicating a potential total loss of 48,600 ton of OC (organic carbon) as result of direct damage to carbon sequestration through consequent accelerated erosion [8]. Considering the average biomass production of forest lands in Lebanon equivalent to $35.64 \mathrm{~m}^{3} \mathrm{ha}^{-1}$ [9], this annual loss exceeds $42,768 \mathrm{~m}^{3}$ and causes carbon emission exceeding 15 ton annually. For this reason, studying the soil forest ecosystem is important for the consideration of reforestation initiatives and management of existing forests to prevent forest fires.

Lebanese soils were described as relatively poor in organic matter content [10]. Therefore, enhancing carbon sequestration by proper management of the soil forest ecosystems is crucial to improve soil properties and tolerance to drought. Mapping and quantifying SOC content and distribution is important for modelling global $\mathrm{C}$ cycles. Unfortunately, direct measurements of soil $\mathrm{C}$ are expensive and time consuming, thus indirect and rapid methods of SOC assessment are of interest to both soil scientists and policymakers. These include semi-quantitative methods such as loss on ignition [11] and thermogravimetry [12], and remote sensing methods such as aerial photography [13] and video imaging [14]. This work used Landsat and IRS (Indian Remote Sensing) to classify land cover and land use, associated with a field survey to map the soil cover and assess carbon stock in the soil and forest ecosystems and link the frequency of forest fires with the soil nature and prevailing land cover and land use to assess the resulting risk of OC loss from the soil pool.

\section{Materials and Methods}

The area of study is the entire Lebanon for the assessment SOC stock in the Lebanese soils and the potential impact of forest fires on carbon loss in the upper soil horizon and entire soil profile. A pilot area was chosen from the western mountain chain located in high Meten area, to assess soil forest association and link SOC stock with the soil nature and type of land cover land use. The area is 14,636 ha with a forest cover of 6,400 ha or $43.7 \%$ of the study area (Fig. 1). It represents a diversity of landforms with gradations from gentle slops to slopping hills, ridges, steep slopes and cliffs. The region is characterized by perennial vegetation cover formed from slightly to moderately dense pine and oak vegetation. Land cover map of the area, at 1:20,000 scale, was produced using visual interpretation of the Indian satellite image IRSAT (4.8 m resolution), merged with multispectral Landsat images, bands 7, 4 and 2 acquired in October 2006 (Fig. 1). Ancillary data, aerial photos, topographic maps at 1:20,000 scale and field truthing were used for checking and validation. Land cover is compatible with Corine and FAO (Food and Agriculture Organization) nomenclature, adapted to fit the Lebanese complex ecosystems [15]. The soil cover of Knaisseh Mountain, high Metn area, located on the western slopes of central Mount Lebanon, forms a topographic and lithologic sequence under different forest systems (Table 1). The general distribution of the soils represents a Catena ranging between $750 \mathrm{~m}$ at Salima and 1,460 m altitude at Falougha. The dominant soil types are Luvisols and Arenosols with associated Leptosols and Cambisols.

The climatic regime ranges from xeric at lower altitudes to subhumid in high mountains with annual rainfall of $1,000 \mathrm{~mm}$ and $1,500 \mathrm{~mm}$ and potential evapotranspiration raging between $1,500 \mathrm{~mm}$ and $1,300 \mathrm{~mm}$ respectively [16]. The mean annual temperature varies between $18{ }^{\circ} \mathrm{C}$ and $13{ }^{\circ} \mathrm{C}$ in the two studied bioclimatic zones.

Correlating the values of SOC density in each soil type corresponding to each soil mapping unit or component is the first step in producing regional SOC distribution maps at county to continental scales. The choice of soil map scale used in the estimation of regional SOC may lead to uncertainty [17] because 


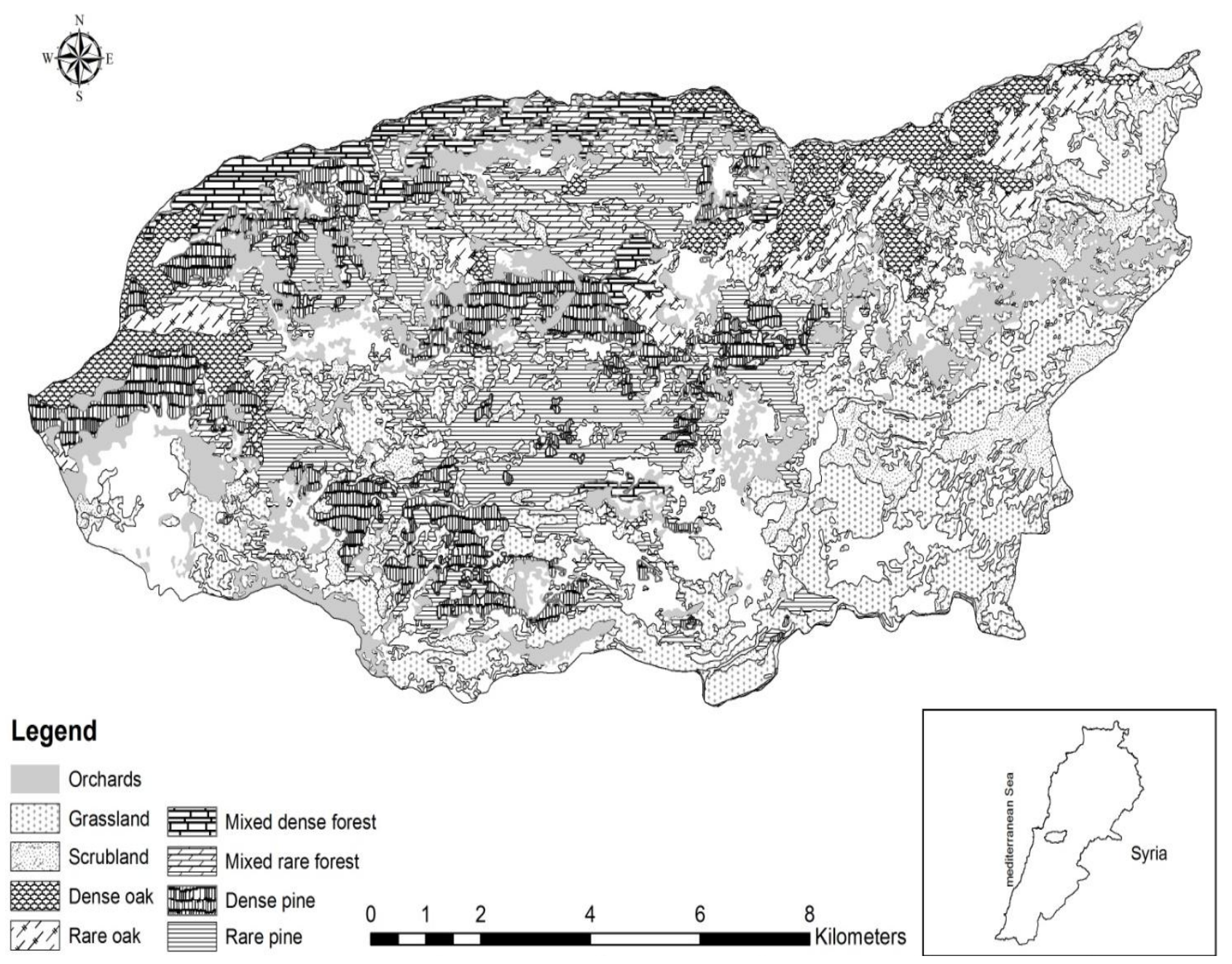

Fig. 1 Land cover of perennial plants species detected from satellite image in High Meten Lebanon.

map delineations and map unit composition vary with scale. In our case the soil map at 1:50,000 scale was used to produce the national SOC stock map. The soil type or soil association was taken as the mapping unit. Within each mapped unit, the mean SOC value of representative profiles was calculated and used for the assessment.

Spatial information is very important in regional SOC studies and comparisons of different maps and scales. Calculating the median or mean of multiple SOC values to represent the SOC value of each mapping unit or component is the most frequently used method for linking soil properties to spatial information [18, 19]. SOC density and stock was assessed using information from 450 soil profiles. A total of 180 representative profiles covering the whole Lebanese territories and reflecting variable pedoclimatic conditions were involved in this study.

The average OC content in a given soil type was calculated involving organic matter content in the soil, bulk density, soil thickness and the content of coarse fragments. The method used for calculating the site "Profile" SOC is shown in the following equation:

$$
S C D_{\text {site }}=\sum_{\text {iquer-1 }}^{j}\left(S O C_{\text {content }} * \text { BulkDensity } * \text { Depth }^{*}(1-\text { frag })\right)
$$


Table 1 Major components of soil forest ecosystems in Lebanese western Mountain chain.

\begin{tabular}{|c|c|c|c|c|c|c|c|}
\hline $\begin{array}{l}\text { Parent rock } \\
\text { and lithology }\end{array}$ & Altitude, $\mathrm{m}$ & $\begin{array}{l}\text { Slope } \\
\text { gradient }\end{array}$ & Dominating land cover & $\begin{array}{l}\text { Dominant } \\
\text { soil type }\end{array}$ & $\begin{array}{l}\text { Soil } \\
\text { depth, } \\
\mathrm{cm}\end{array}$ & $\begin{array}{l}\text { Average } \\
\text { SOC } \\
\text { content, } \\
\%\end{array}$ & $\begin{array}{l}\text { Total SOC } \\
\text { stock, ton/ha }\end{array}$ \\
\hline \multirow{3}{*}{$\begin{array}{l}\text { Hard limestone } \\
\text { calcareous }\end{array}$} & 750 & Steep & Dense shrubs, grasses and residual oak & Luvisols & $0-10$ & 2.00 & \multirow{3}{*}{98.39} \\
\hline & 780 & Steep & Mixed dense forest, shrubs, grasses & & $10-40$ & 1.35 & \\
\hline & 840 & Rolling & Oak, Pinus halepensis, grasses. & Leptosols & $40-60$ & 0.59 & \\
\hline \multirow{5}{*}{$\begin{array}{l}\text { Sandstone } \\
\text { non calcareous }\end{array}$} & 900 & Sloping & Dense Pinus pinea & \multirow{5}{*}{$\begin{array}{l}\text { Arenosols } \\
\text { and } \\
\text { Cambisols }\end{array}$} & & & \multirow{5}{*}{133.62} \\
\hline & 1,050 & Undulating & Dense Pinus pinea, rare oak & & $0-25$ & 1.42 & \\
\hline & 1,200 & Rolling & Rare Pinus pinea, sparse oak & & $25-90$ & 1.06 & \\
\hline & 1,300 & Steep & Very dense Pinus pinea, shrubs, grasses & & $90-200$ & 0.45 & \\
\hline & 1,460 & Steep & Dense Pinus pinea, shrubs, rare grasses. & & & & \\
\hline
\end{tabular}

\section{Results and Discussion}

\subsection{Carbon Stock in Lebanese Soils}

A total of 11 soil types (major classes) represented the mapping units describing the higher soil component or major classes were identified in Lebanon. These are in increasing area order Andosols, Gelysols, Regosols, Vertisols, Fluvisols, Anthrosols, Cambisols, Arenosols, Calcisols, Luvisols and Leptosols with a total SOC density ranging between 29.63 ton/ha and 138.68 ton/ha in Leptosols and Cambisols respectively. The total SOC stock for the Lebanese territories is about $38,047,122$ tons in the upper $30 \mathrm{~cm}$ and $83,184,528$ tons for the three horizons (upper $100 \mathrm{~cm}$ soil depth). The spatial distribution of total SOC reserve in the entire soil is represented in Fig. 2.

Within each unit, the calculation of the mean value of representative profiles revealed a standard deviation varying between 16.2 tons in Andosols and 80 tons in Luvisols. The higher standard deviation observed in Luvisols reflects soil diversity, old history and different management practices [8].

SOC unpredictability in managed soils after the shift from natural vegetation to different cropping systems depended on historical and actual landuse pattern. The analysis of SOC stock in the upper soil layer revealed that Leptosols, which can be also classified as Lithic Luvisols, ounce famous for being named as terra-rossa of the Mediterranean Lebanese slopes, are often found in association with deep
Luvisols. This soil group contains the largest amount of carbon stock exceeding 10.78 million tons. Leptosols are usually shallow soils spread on slopping lands over hard limestone, a fact making them highly vulnerable to water erosion; therefore, they need special care and attention for the development and implementation of protection policy. Leptosols are receiving the highest anthropic pressure due to the historical deforestation and recent large forest fires in the country. The assessment of landcover influence on soil evolution showed the prevalence of forest/shrub vegetation on Leptosols. Even the Leptosols encountered on the eastern Lebanese mountain chain under more arid climatic conditions and rare vegetation cover were ranked in the fourth place with more than 4 million tons of total SOC, which can indicate the impact of relict forest that has been subject to continuous clearing.

Luvisols are distinguished by the prevalence of natural vegetation with different rates of shift to cultivation. They rank second in terms of the SOC stored in the upper layer with 4.82 million tons. Luvisols show variable content of SOC varying between $4 \%$ in North Lebanon at $500 \mathrm{~m}$ altitude under forest and shrubs and $0.7 \%$ on the coastal area under sparse grass vegetation. In general, the location of Luvisols and Leptosols in the Lebanese landscape indicates their genetic parenthood and their morphology reflects the altitudinal functional relationship along catenary transects [20]. The characteristics of cambisols, spread all over Lebanon, show that SOC variability 


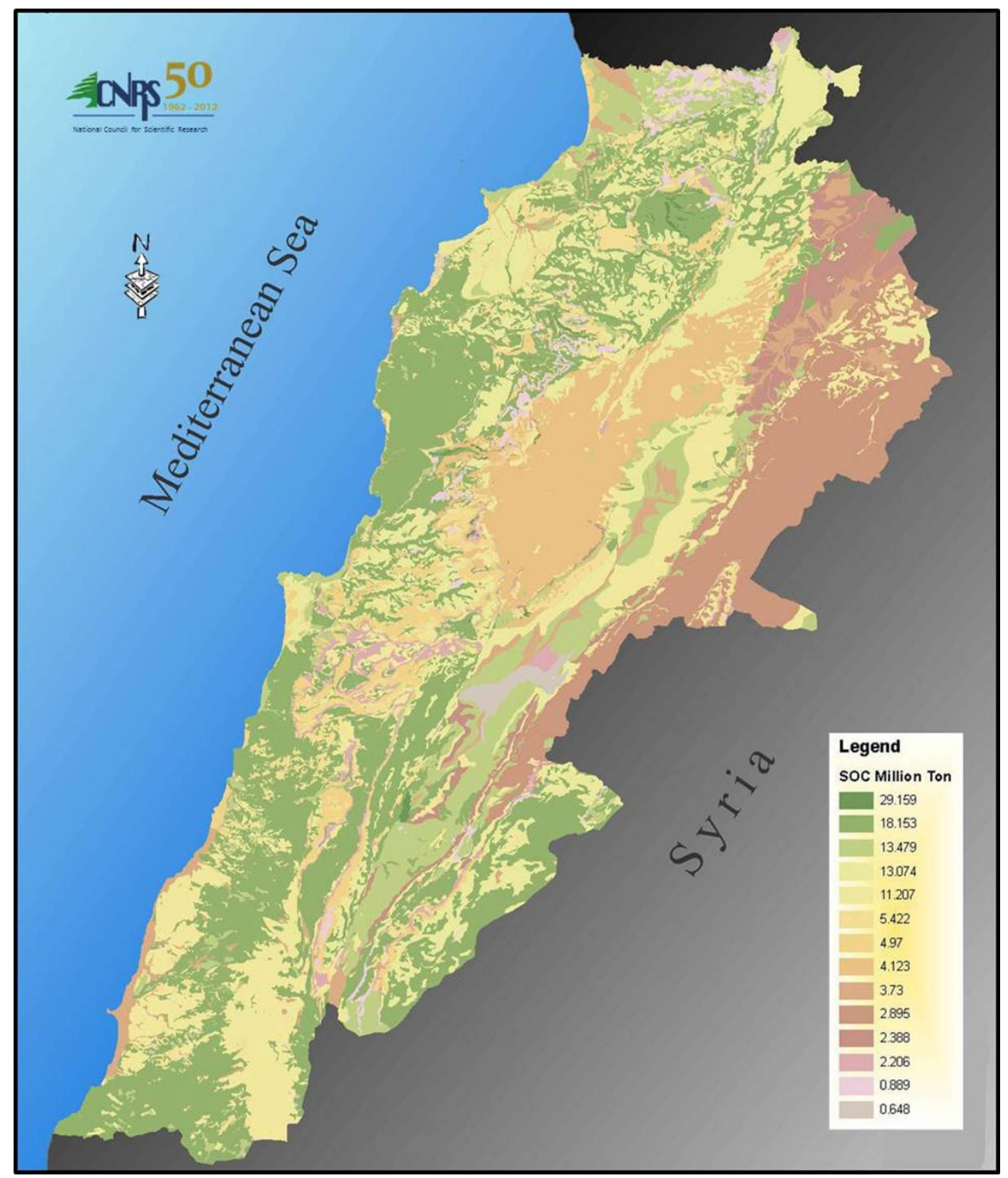

Fig. 2 Spatial distribution of total SOC stock in the soil profile $(100 \mathrm{~cm}$ depth) of Lebanon.

is due to the diversity of landcover and land use. Cambiosls (profile LB 6) in Halba area (north Lebanon) are relatively high in OC stock being under potato and corn cultivation with organic amendment. The same soil type (profile LB 261) in Marjayoun (South Lebanon) is relatively low in organic carbon stock. The soil is covered by olive trees known for being the most extensive, rainfed, agricultural practice in the country.
The updated information on SOC retrieved from the soil and terrain database at 1:50,000 scale showed that cambisols are in general richer in OM (organic matter) content compared to Luvisosls. They contain an average of 45 ton/ha in the upper soil horizon compared to 36 ton/ha in Luvisols. The distribution of these soils on different slope gradients and the higher risks of water erosion on Luvisols, beside landuse pattern, could be behind this difference in SOC 
density in both soil types. Among the studied profiles, some $57.5 \%$ of cambisols and $55 \%$ of Luvisols contained a mean SOC density in the topsoil below the average values per type, which might be related to human impact and to the effect of different agricultural practices and erosion-sedimentation resulting in SOC loss or accumulation. However, Anthrosols located mainly on terraces and cultivated under perennial fruit trees show high SOC density and stock, notably under integrated and organic production, which make them comparable with forest soils and distinct from cambisols and luvisols increasingly used for field crops production requiring frequent tillage. These results agree with the findings of Ref. [21], which compared the organic carbon storage in conventional and organic farming and [22], analysed the impact of no till practices on $\mathrm{OC}$ accumulation in abandoned olive orchards.

Unsurprisingly Calcisols, Andosols and Vertisols represented the lowest SOC storage due to their origin, rock-soil-plant interactions and soil physico-chemical properties. Comparing the values of SOC in surface soil layer with the overall SOC density and stock in Lebanese soils showed a good correlation (0.98) between the SOC stock in topsoil and subsoil, indicating the dominant role of the upper, biologically most active soil horizon, in the organic matter accumulation and carbon sequestration. Therefore, we need to protect this asset from erosion and fires.

\subsection{Carbon Stock in High Meten Area}

\subsubsection{Land Cover Impact on SOC}

Two principal soil groups derived from calcareous hard limestone and non-calcareous sandstone were identified in the study area (Table 1). The calcareous soil group consists of Luvisols with associated Cambisols. The vegetation in the region consists of residual oak, shrubs (Spartium junceum, Pistacia palaestina, and Styrax officinalis) and grasses. Although soil types are relatively not deep, some individual profiles may exhibit distinct characteristics due to old soil conservation measures like terraces. The non-calcareous soil group consists of Arenosols with associated Cambisols and Andosols. Soil is developed into deep and differentiated profile due to the stabilizing effect of the forest cover and favourable climatic conditions. The absolute dominance of Pinus pinea in this mountain ecosystem indicates the association of pine with the non-calcareous, sandy soil type. The erosion-deposition processes markedly affect soil units representing the transition between the two soil groups. The soil cover on colluvial deposits is stabilized by old terraces and usually cultivated by local farmers under fruit trees and olives.

Pine occupies the largest area of forest in the High Meten (3,600 ha) followed by oak (1,800 ha) and mixed forest $(1,200 \mathrm{ha})$, representing $54.5 \%, 27.3 \%$ and $19.1 \%$ of forest cover respectively. Mapping of the SOC stock under current land cover and land use in High Meten area showed the highest SOC stock in the area under natural and manmade fruiting pine forest (Fig. 3).

The calculation of the SOC stock in the surface horizon showed a clear effect of pine forest on organic matter accumulation in the soil which provided the conditions for the accumulation of more than 411 thousand tons of total $\mathrm{OC}$ despite their young age going back to the seventeen century where seeds were introduced from Tuscana, Italy and propagated on sandy Lebanese mountains soils (Fig. 4). The second place belongs to grasses, which bring more annual green mass to the soil favoured by the seasonal rainfall amount and dry season. Thus, it was not surprising that rare pine accumulated more SOC than the dense pine due to the rich under storey under the first class. The same trend was followed by other species grouped under mixed forest and oak, which accumulated up to $24 \%$ more SOC due to grass development and regeneration under rare forest stands.

The analysis of SOC density in the soil of the pilot area showed relatively higher average organic matter accumulation rate in the soil under forest stands 


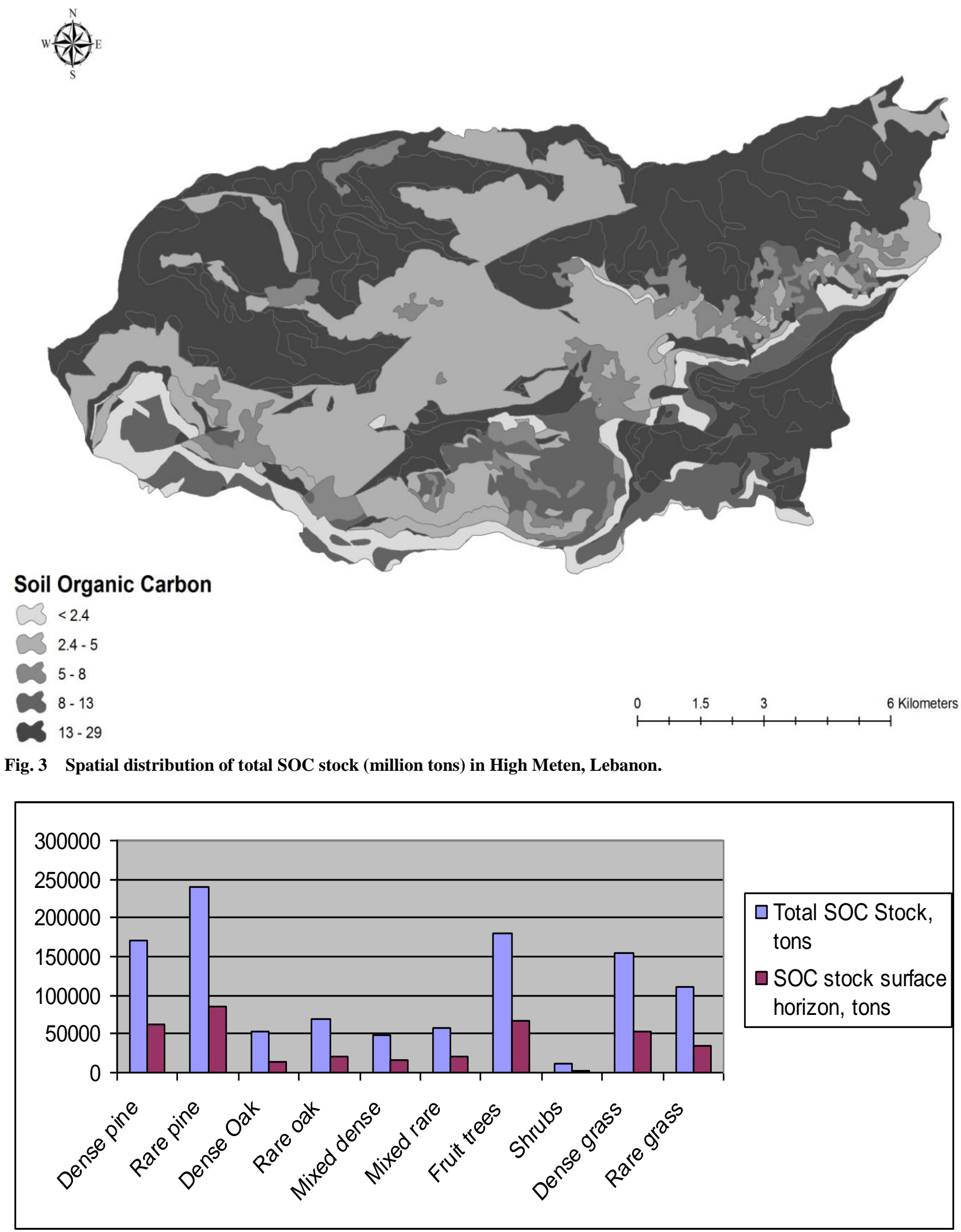

Fig. 4 Total SOC stock under different vegetation cover of High Meten area. 


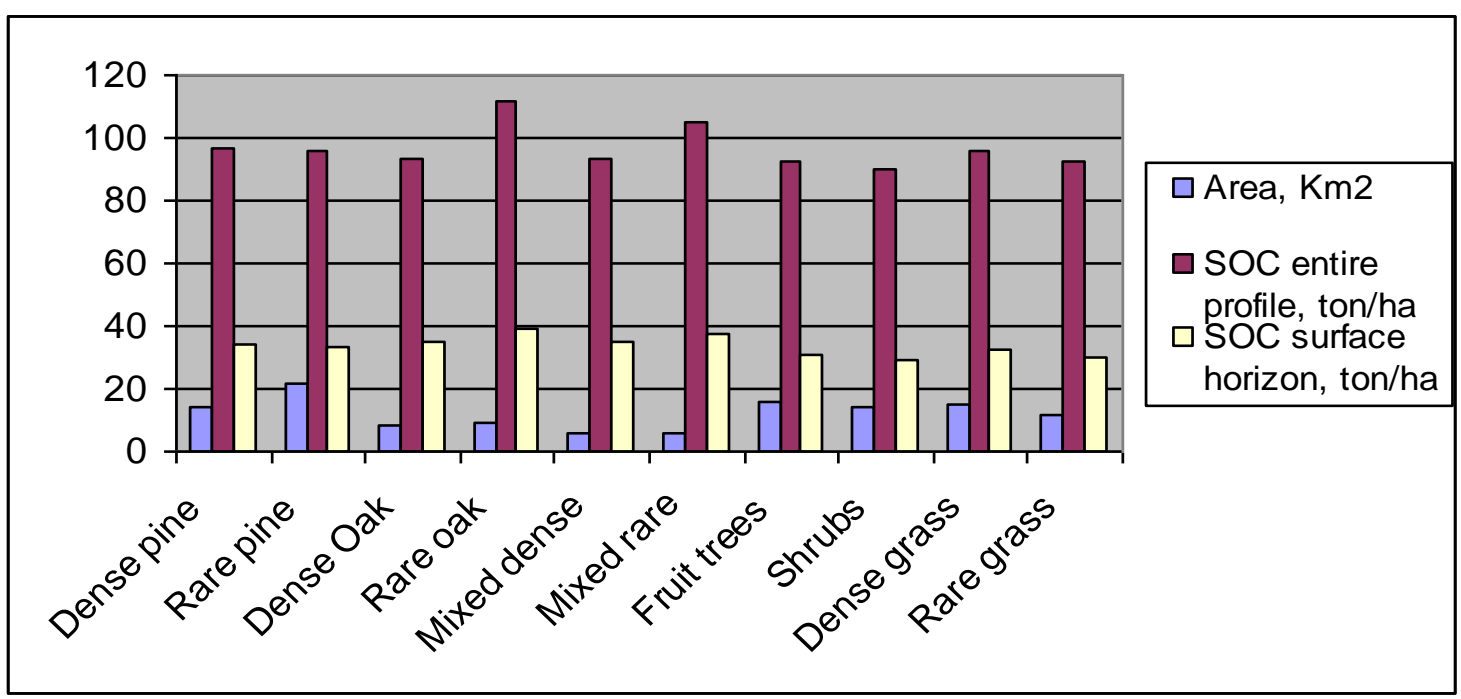

Fig. 5 SOC density under different vegetation cover and land use in High Meten, Lebanon.

compared to shrubs and agricultural lands both in topsoil (33.5 ton/ha) and (30 ton/ha) and in the entire soil profile (99 ton/ha) and (91 ton/ha) respectively (Fig. 5). In both cases grassland showed a comparable rate of SOC density with the arable lands (fruit trees), indicating slight effect of minimal cultivation and traditional conservation agriculture on organic matter mineralisation and SOC sequestration.

\subsection{Effect of Forest Fires on SOC Loss}

The total area of forest land in Lebanon was estimated at 139,100 ha with a total biomass production equivalent to $4,967,361 \mathrm{~m}^{3}$ or 359,000 tons [23]. Given that one $\mathrm{m}^{3}$ of wooded land is equivalent to 0.36 ton $\mathrm{C}$ [24], the total above ground $\mathrm{C}$ in the Lebanese forest area is estimated at 1,795,000 tons. At the national level, a total of 1,446 fires occurred between 2003 and 2010 distributed mainly in the central parts of the northern and southern regions and along the western coastal Lebanese mountains (Fig. 6). The number of fires varied between 520 (2003), 158 (2005), 652 (2007) and 116 (2010), damaging a total forest and cultivated area of $4,518.85$ ha, equivalent to $1.25 \%$ of national green area.

The general trend of fires-soil relationship for the observed years shows more frequent fires on sandy soils (Arenosols), gravely soils (Regosols, Luvisols) and notably shallow (Leptosols) distinguished by high erosion rates and enrichment with coarse fragments (Fig. 7). These soils are characterized by lower water holding capacity as compared to deeper and clay soils like Cambisols, Fluvisols and Gleysols with higher water retention capacity and residual moisture reserve supporting plant resilience to drought during the dry period stretching between May and November. The burned area on these soil types in 2003 did not exceed 50 ha while in the first soil group it reached 700 and 1,500 ha.

The most vulnerable areas to fires are agricultural and urban lands mixed with forest and agriculture (Fig. 8). This indicates the increased risk from anthropic pressure on green cover in the country. Among land use components, olive is known for drought tolerance, therefore, it represents the least burned area in 2003 (31.45 ha) versus 75.42 ha for field crops and 453.78 ha for fruit trees.

Increased vulnerability to fires was observed in the two last classes due to prevailing practice of burning plant residue after harvest notably in wheat cultivation on nesting lands. Another factor multiplies the vulnerability of field crops and fruit trees to fires, i.e., the inherited low tolerance of irrigated fruit trees and field crops to drought incidences if exposed to long hydric stress. Abandoned lands, grassland and pine 
$N$
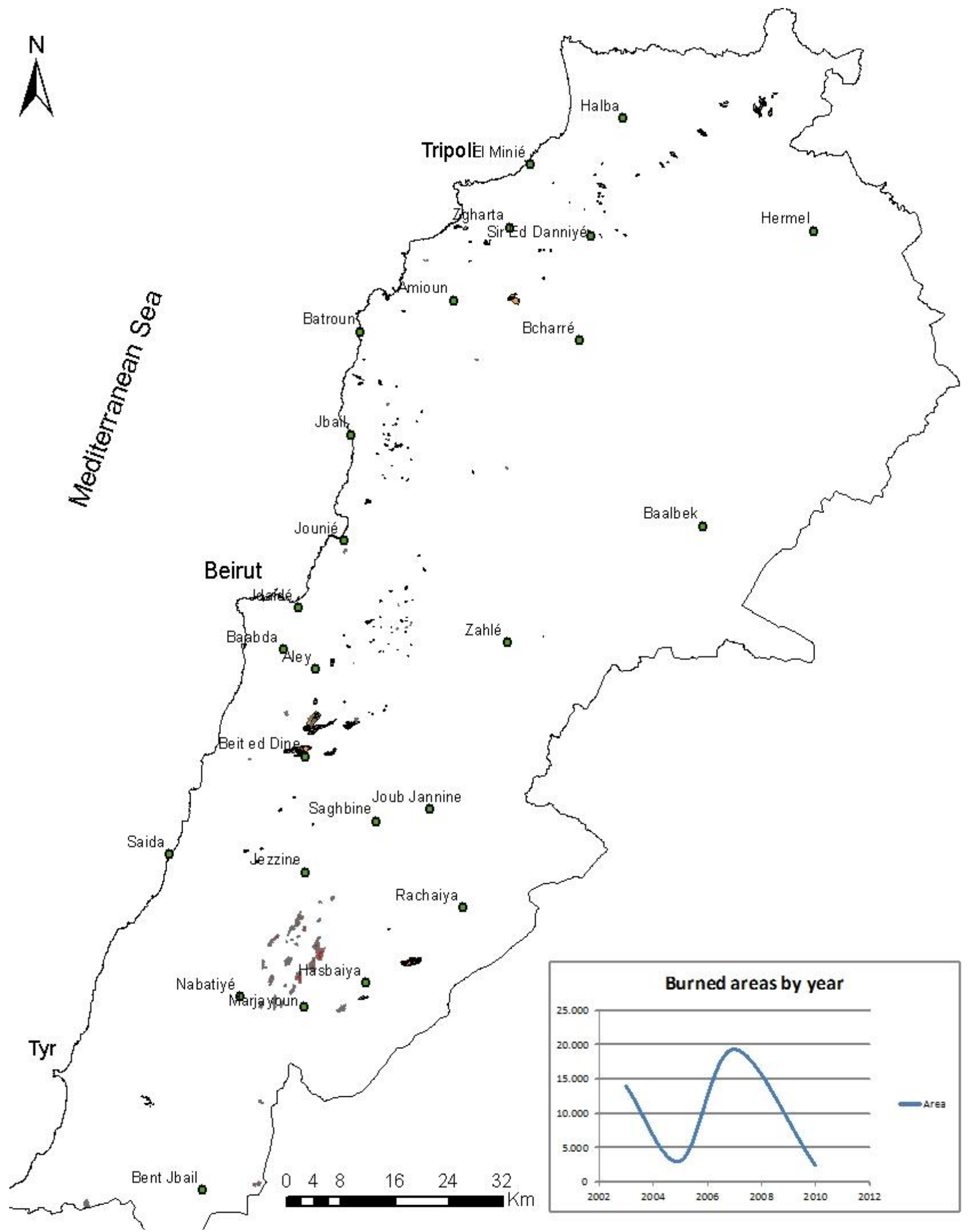

Fig. 6 Spatial distribution of forest fires between 2003 and 2010. 

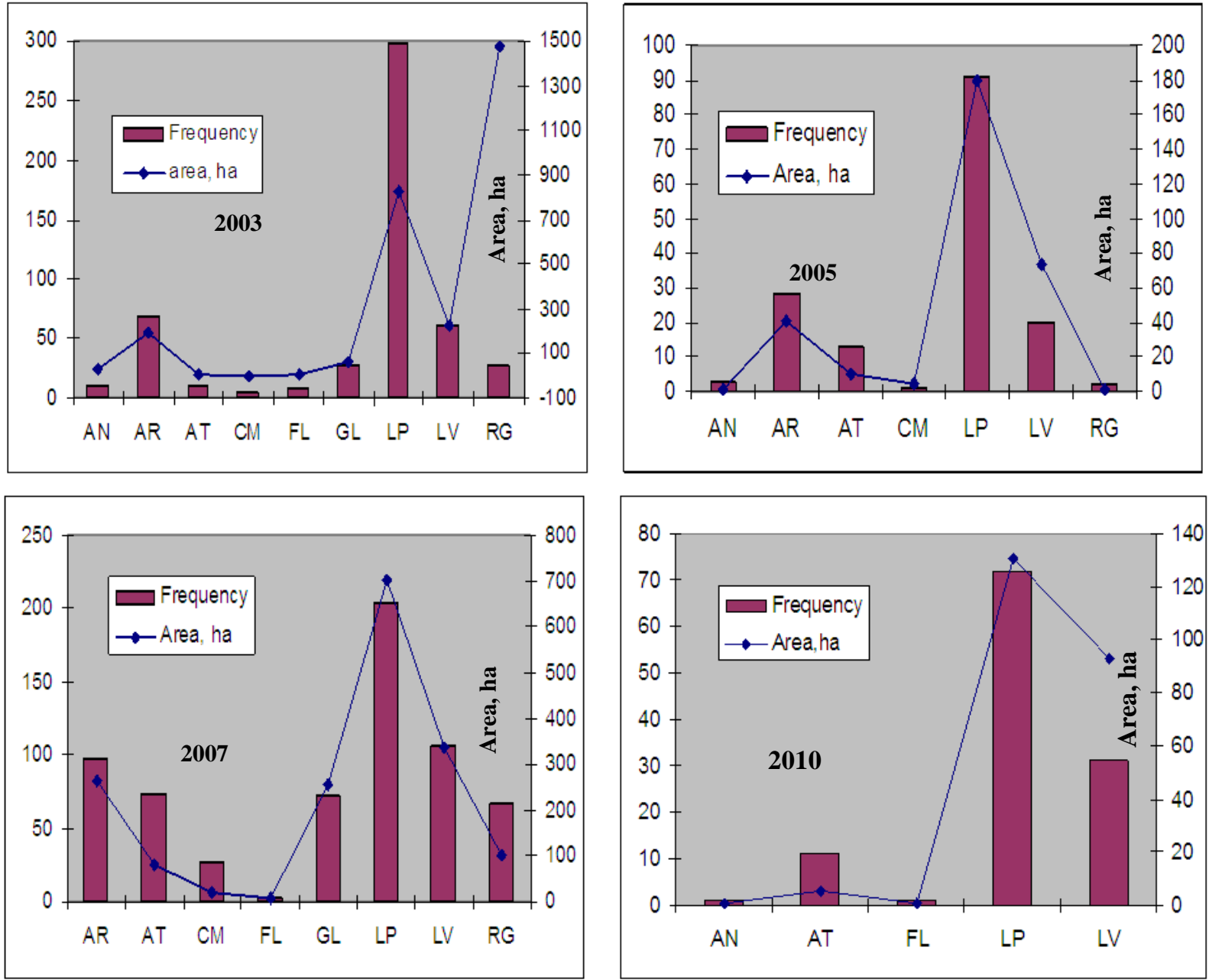

Fig. 7 Frequency of fires on different mountain Lebanese soils.

AN: Anthrosols; AR: Arenosols; CM: Cambisols; FL: Fluvisols; GL: Gleysols; LP: Leptosols; LV: Luvisos; RG: Regosols.
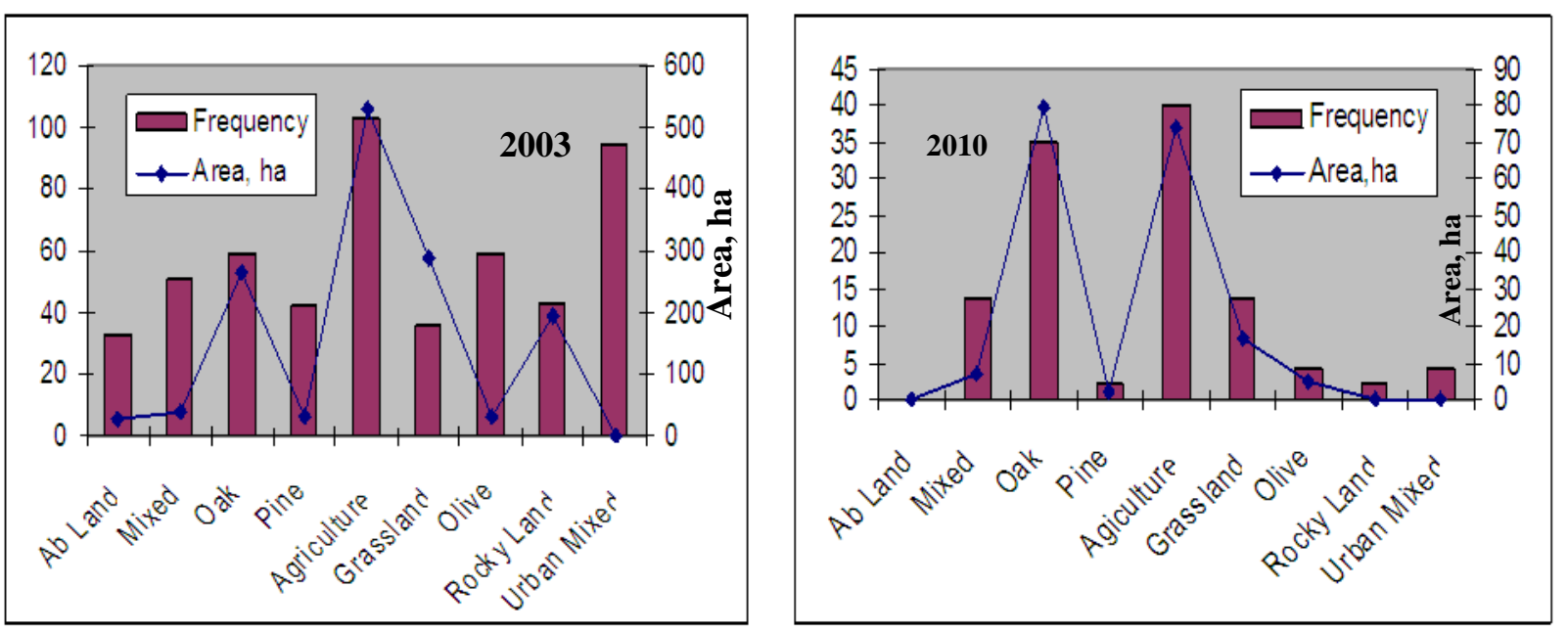

Fig. 8 Frequency of fires on different land cover and land use. 
were the least exposed to fires notably in 2010, which witnessed the least number of fires compared to the catastrophic forest fires of 2007. Due to their distribution at lower altitudes and increased human pressure, oak and mixed forests exhibited increased exposure to fire frequency with eventual expansion of burned areas.

\section{Conclusion}

Depending on their origin and location, the Lebanese soils show large variability in SOC content and storage in the topsoil and subsoil. The amounts of SOC stored in the upper soil layer were $35,618,112$ million tons while those accumulated in the $100 \mathrm{~cm}$ depth reached 83,184,528 million tons. Beside other factors, SOC density and stock depend closely on soil origin and nature and historical and current land cover land use. The estimation of SOC stock in Lebanese soils showed clear relation with the type of forest but it increased in the forest-grass association, grasslands and in rare forest compared to dense forest. Assessing the SOC stock in each soil type and relating it to the soil characteristics, type of land cover and land use and correlating them to forest fires incidences in soil forest ecosystems is necessary to assess the vulnerability of soil-forest association to climate change and drought. To link the soil properties to spatial information and represent the SOC value of each map unit the median or mean of multiple SOC values from 180 representative soil profiles were calculated involving organic carbon content in the soil, bulk density, soil thickness and the content of coarse fragments. Soil mapping and assessment was integrated with the mapping of land cover and land use using satellite images to analyze the soil forest association and forest fire impact on SOC potential loss. Time series data on fires occurring between 2003 and 2010 were used to assess the frequency of fires in relation to soil characteristics and the type of vegetation cover. Most frequent forest fires were observed on poor, skeletic and shallow mountain soils with sandy loam texture and low water retention capacity. Similarly, fires of high frequency were observed on deep, clay, cultivated soils and soils mixed with urban expansion and agricultural land uses as a result of human mismanagement. An attempt was made to assess the effect of fires on SOC with the aim to present updated information integrating remote sensing, GIS, soil classification and observed forest fires to serve awareness rising and support decision making for the implementation of national plans to combat desertification in Lebanon.

\section{References}

[1] Post, W. M., Peng, T. H., and Emanuel, W. R. 1990. "The Global Carbon Cycle." Am. Sci. 78: 310-26.

[2] Eswaran, H., Van Den Berg, E. V., and Reich, P. 1993. "Organic Carbon in Soils of the World." Soil Sci. Soc. Am. J. 57: 192-4.

[3] Lal, R., Kimble, J. M., Follett, R. F., and Cole, C. V. 1998. The Potential of U.S. Cropland to Sequester Carbon and Mitigate the Greenhouse Effect. Ann Arbor: Ann Arbor Press.

[4] Kimble, J. M., Eswaran, H., and Cook, T. 1990. "Organic Carbon on a Volume Basis in Tropical and Temperate Soils." Presented at Transactions of the 14th International Congress of Soil Science (Volume 248-53). Commission V. International Society of Soil Science, Kyoto, Japan.

[5] Tan, G., and Shibasaki, R. 2003. "Global Estimation of Crop Productivity and the Impacts of Global Warming by GIS and EPIC Integration." Ecol. Modell. 168 (3): 357-70.

[6] Janzen, H. H. 2004. "Carbon Cycling in Earth Systems-A Soil Science Perspective." Agric. Ecosyst. Environ. 104 (3): 399-417.

[7] Mitri, G. 2009. Lebanon's National Strategy for Forest Fire Management. Beirut, Lebanon: AFDC.

[8] Darwish, T., and Fadel, A. 2017. "Mapping of Soil Organic Carbon Stock in the Arab Countries to Mitigate Land Degradation." Arab J. Geosci, Springler 10 (21): 474. https://doi.org/10.1007/s12517-017-3267-7.

[9] Beydoun, G. Y., and Stephan, J. 2005. National Forest Assessment Program Lebanon. Data Analysis Report by Genane Youness Beydoun-FAO Data Analysis Expert \& Jean Stephan Agricultural Engineer, MOA, Lebanon.

[10] Darwish, T., Khawlie, M., Jomaa, I., Abou Daher, M., Awad, M., Masri, T., Shaban, A., Faour, G., Bou Kheir, R., Abdallah, C., and Haddad, T. 2006. Soil Map of Lebanon 1/50000. CNRS-Lebanon, Monograph Series 4, 
p. 367.

[11] Konen, M. E., Jacobs, P. M., Burras, C. L., Talaga, B. J., and Mason, J. A. 2002. "Equations for Predicting Soil Organic Carbon Using Loss-on-Ignition for North Central U.S. Soils.” Soil Sci. Soc. Am. J. 66: 1878-81.

[12] Siewert, C. 2004. "Rapid Screening of Soil Properties Using Thermogravimetry." Soil Sci. Soc. Am. J. 68: 1656-61.

[13] Chen, F., Kissel, D. E., West, L. T., Rickman, D., Luvall, J. C., and Adkins, W. 2005. "Mapping Surface Soil Organic Carbon for Crop Fields with Remote Sensing." J. Soil Water Conserv. 60 (1): 51-7.

[14] Fox, G. A., and Sabbagh, G. J. 2002. "Estimation of Soil Organic Matter from Red and Near-Infrared Remotely Sensed Data Using a Soil Line Euclidean Distance Technique." Soil Sci. Soc. Am. J. 66 (6): 1922-9.

[15] CNRS. 2009. Land cover map of Lebanon at 1:20,000 scale. Beirut, Lebanon.

[16] Nimah, M. 1992. "Irrigation Requirements in Lebanon." In Proceedings of the First National Conference on Water in Lebanon. UNICEF. 27-28. Beirut, Lebanon, 13-25.

[17] Arnold, R. W. 1995. "Role of Soil Survey in Obtaining a Global Carbon Budget.” p. 257-63. Edited by R. Lal et al.
Soils and Global Change. Adv. Soil Sci. FL: CRC Press, Boca Raton.

[18] Martial, B., Carvalho, M., Volkoff, B., and Cerri, C. C. 2002. "Brazil's Soil Carbon Stocks." Soil Sci. Soc. Am. J. 66: 888-96.

[19] Bajtes, N. H. 2000. "Effects of Mapped Variation in Soil Conditions on Estimates of Soil Carbon and Nitrogen Stocks for South America." Geoderma 97: 135-44.

[20] Darwish T., and Zurayk, R. 1997. "Distribution and Nature of Red Mediterranean Soils in Lebanon along an Altitudinal Sequence." CATENA 28: 191-202.

[21] Fließbach, A., Oberholze, H. R., Gunst, L., and Mäde, P. 2007. "Soil Organic Matter and Biological Soil Quality Indicators after 21 Years of Organic and Conventional Farming." Agriculture, Ecosystems and Environment 118 (1): 273-84.

[22] Atallah T., Sitt, K., Asmar, E. E., Bitar, S., Ibrahim, L., Khatib, M. N., and Darwish, T. 2015. "Effect of Abandonment of Olive Orchards on Soil Organic Carbon Sequestration in Mediterranean Lebanon." Soil Research 53 (7): 745-52. http://dx.doi.org/10.1071/SR14170.

[23] FAO/MoA. 2005. National Forest and Tree Assessment and Inventory TCP/LEB/2903. Final Report. Beirut, Lebanon. 